age $=41.6(10.1)$ years), and eight men (mean (s.d.) age $=46.3(9.4)$ years). Three women were divorced and the other eight married, contrasting with two married men, one separated man and four single, i.e. never married, men, among the seven for whom this data was recorded.

The mean (s.d.) age of the onset of drinking was 21.8 (7.6) years for the women compared with 17.8 (2.7) years in the men. Men had drunk for 26.7 (10.2) years before seeking treatment compared with 18.0 (7.2) years in women. Of the women, eight had suffered from medical complications, compared with only three of the men. Women were more likely to drink at home on their own than men $(81.8 \%$ compared with $42.9 \%$ ).

While numbers in our sample were too small to allow a statistical analysis, these results agree with earlier studies (e.g. Leyland, 1982; Schmidt et al, 1990 ) in suggesting that women present to psychiatric services at a similar age to men but with a shorter history of drinking. They are more prone to the medical sequelae of heavy drinking and more likely to drink alone.

We were surprised to find women in our sample drank more heavily than the men, drinking on average 23.7 (14.9) units of alcohol per day compared with 18.0 (7.0) units in the men, contrary to work suggesting that male problem drinkers are the heaviest drinkers (Schmidt et al, 1990). We were also interested to note that of eight married women only two reported marital problems. Both the married men felt their marriage was in jeopardy and thus no males had a stable relationship, although factors other than alcoholism might have accounted for the low relationship rate in the men.

This study reminds us of several facts. Firstly, the number of females referred for help with alcoholrelated problems is increasing disproportionately with respect to male referrals. Secondly, women drinkers often have specific problems needing to be addressed which are less apparent or absent in male drinkers, for example, greater risk of stigmatisation or medical sequelae. Lastly, as many women drink at home, it may be less obvious that alcohol is a problem. It is notable that there is little work done on gender difference in alcohol problems and that only one voluntary agency has a designated service for female problem drinkers. We therefore feel it is important to draw this rising problem to the attention of the non-specialist general psychiatrist.

LeYLAND, J. (1982) Gender, drinking and alcohol abuse. In Gender and Psychopathology (ed. I. Al-Issa), pp. 201-220. New York: Academic Press.

MADDEN, J. S. (1984) A Guide to Alcohol and Drug Dependence. Bristol: Wright.
SChmidt, C.. KleE, L. \& Ames, G. (1990) Review and analysis of literatures on indicators of women's drinking problems. British Journal of Addiction. 85, 179-192.

S. D. SMITH

The John Conolly Hospital

F. OYEBODE

Bristol Road

South Rednal

Birmingham B45 9BD

\section{Cyproterone acetate therapy and aggression}

SIR: The recent correspondence from Thibaut et al (Journal, August 1991, 159, 298-299) on the potential benefits of cyproterone acetate therapy in aggression is both stimulating and a source of concern. Recent experience in our hospital has led to some doubts regarding the use of this medication, particularly with elderly patients. The following case history will demonstrate this point.

Case report. $\mathrm{Mr} \mathrm{X}$, a 70-year-old long-term patient in our hospital, had long been a problem due to his proclivity for fondling the female staff and female patients, at every available opportunity. This behaviour had defied numerous behavioural strategies designed to curb his activities. Staff frustration was understandable as numerous violent incidents had developed between $\mathrm{Mr} \mathrm{X}$ and other patients on the unit. A trial of cyproterone acetate, at a dose of $50 \mathrm{mg}$ twice daily, was commenced, and the patient's behaviour was observed.

Over a two-week period, $\mathrm{Mr} \mathrm{X}$ became progressively more inactive, and he tended to spend more time sitting in a chair - he had previously been very physically active. His attempts to fondle patients and staff did not diminish, however, as he would reach out and fondle any female in the vicinity. Over time we observed that $\mathrm{MrX}$ had become quite immobile, and he would fall from standing when staff helped him walk. He suffered several falls resulting in a number of minor injuries. Active mobilisation did not produce significant benefit. Marked atrophy of the quadriceps muscles was noted bilaterally. Cyproterone acetate therapy was discontinued after one month, and within two weeks, $\mathrm{Mr} \mathrm{X}$ was again fully mobile, and his behaviour was unchanged. His quadriceps muscles have increased almost two centimetres in circumference, and he has had no further falls.

Our experience with cyproterone acetate has not been a favourable one. Admittedly, our elderly patients are often treated for sexual aggression, but the responses we have observed are not favourable, with problems of a different nature developing. Our experience in the treatment of over a dozen cases of sexually aggressive males and females has led us to believe that cyproterone acetate therapy is fraught with difficulties. Certainly, there may be a role for this drug in selected cases of aggressive behaviour, 
but in elderly patients we have found more problems are created than are solved.

\author{
Alberta Hospital Ponoka \\ Box 1000 \\ Ponoka, Alberta \\ TOC $2 \mathrm{HO}$ \\ Canada \\ The Grey Nuns Hospital \\ Edmonton, Alberta \\ Canada
}

Alan Byrne
Bryan Brunet

Paul McGanN

\section{Post-stroke rapid cycling bipolar affective disorder}

SIR: Blackwell (Journal, August 1991, 159, 279-280) reports the case of a young man who developed a rapid-cycling manic-depressive illness complicating a small brain stem haematoma. The following case report further illustrates the phenomenology of mood swings occurring in a patient who developed a very rapid-cycling affective disorder following a right hemisphere cerebrovascular accident.

Case report. The patient was a 44-year-old ambidextrous man who suffered an ischaemic infarct involving the right hemisphere (mainly temporo-insular and anterior parietal regions) that left him with a left hemiparesis and a left arm dystonia. He had a previous history of alcohol abuse but no positive family or personal history of affective disorder. Two months after his stroke, his wife noted that he began to experience abrupt changes in mood, even within a few hours, from jocularity to helplessness, and from talkativeness to elective mutism. Affective states were evaluated on repeated occasions using the Hamilton Rating Scale for Depression (HRSD) and the Mania Scale (MAS; Beck et al, 1986). During the manic phases he appeared distractible and elated, and joked inappropriately. At times he was irritable and occasionally exploded into a rage with only trivial precipitants. He also showed loud, pressured speech, flight of thoughts, and increased libido and activity. Through several manic episodes, his MAS score ranged from 13 (hypomania) to 18 points (definite mania). During depressive phases, he appeared apprehensive and forgetful, and showed a pessimistic attitude towards the future and total loss of libido. His HRSD scores were always above 16 points (major depression). It was noted that over a period of two weeks the patient had at least three mood swings per day. Bipolar cycles with intervening euthymic periods and very brief mixed affective states were also documented. The patient was started on treatment with carbamazepine $(600 \mathrm{mg} /$ day $)$, but he developed intolerable side effects, and the medication was discontinued. Lithium carbonate was then prescribed but it was withdrawn because of noncompliance. Rapid cycling spontaneously subsided one year after onset.
The phenomenological profiles of post-stroke depression and mania are both remarkably similar to those found in patients with functional affective disorders (Starkstein \& Robinson, 1989). Furthermore, seasonal patterns of bipolar illness (Hunt \& Silverstone, 1990) and unipolar mania (Berthier et al, 1990) have been reported after focal involvement of the limbic system. The occurrence of very rapid mood fluctuations between mania and depression alternating every two weeks in Blackwell's patient and on an hour-by-hour basis in the present case also parallels that of functional rapid-cycling bipolar affective disorder (Wolpert et al, 1990). Focal damage to the limbic system affecting midline structures (Blackwell, 1991) or the right hemisphere might be implicated in the pathogenesis of rapid-cycling bipolar affective disorder.

Bech, P., Kastrup, M. \& Rafaelsen, O. J. (1986) Minicompendium of rating scales for states of anxiety, depression, mania, and schizophrenia, with corresponding DSM-III syndromes. Acta Psychiatrica Scandinavica, 73 (suppl. 236), 29-31.

Berthier, M. L., Starkstein, S. E., Robinson, R. G., el al (1990) Limbic lesions in a patient with recurrent mania. Journal of Neuropsychiatry, 2, 235-236.

Hunt, N. \& Silverstone, T. (1990) Seasonal affective disorder following brain injury. British Journal of Psychiairy. 156, 884-886.

Starkstein, S. E. \& Robinson, R. G. (1989) Affective disorders and cerebral vascular disease. British Journal of Psychiatry, 154, $170-182$.

Wolprert, E. A., Goldberg, J. F. \& Harrow, M. (1990) Rapid cycling in unipolar and bipolar affective disorders. American Journal of Psychiatry, 147, 725-728.

Neurology Service,

MARCElo L. Berthier

Virgen de la Victoria University Hospital

Colonia Sta Inés $\mathbf{s} / \mathbf{n}$

Apartado 3091 (29001)

Málaga

Spain

Fluvoxamine withdrawal syndrome

SIR: Fluvoxamine is a selective 5-hydroxytryptamine (5-HT) uptake inhibitor that has been shown to be effective in the treatment of obsessive-compulsive disorder (OCD) (Goodman et al, 1990). I report here a patient who developed a distinct psychiatric syndrome whenever she stopped her fluvoxamine medication.

Case report. The patient was a 30-year-old woman in 1987 when her medication with fluvoxamine was started. She had a long history of OCD; the illness started at age 12 with compulsive hand-washing and bathing. Over the years her symptoms fluctuated; although there were a couple of years of good functioning, she was usually severely incapacitated 